\title{
CAPÍTULO 08: DESAFIOS ENFRENTADOS COM O USO DE NOVAS TECNOLOGIAS: ENSINO E APRENDIZAGEM EM PERÍODO DE PANDEMIA COVID-19
}

\author{
CAPÍTULO 08: DESAFÍOS ENFRENTADOS CON EL USO DE NUEVAS \\ TECNOLOGÍAS: ENSEÑANZA Y APRENDIZAJE EN PERÍODO DE PANDEMIA \\ COVID-19
}

\section{CHALLENGES FACED WITH THE USAGE OF NEW TECHNOLOGIES: TEACHING AND LEARNING IN COVID-19 PANDEMIC PERIOD}

\author{
Guilherme de Siqueira Freitas Pontes ${ }^{1}$; Dayane Camile Bezerra de Lima ${ }^{2}$; Simone de Paula Silva ${ }^{3}$. Derek Luiz \\ Alves dos Santos ${ }^{4}$; Erick Viana da Silva ${ }^{5}$
}

DOI: https://doi.org/10.31692/978-65-88970-06-5.116-132

\begin{abstract}
RESUMO
Este artigo acadêmico foi idealizado a partir de reflexões sobre a necessidade em gerar discussão e conhecimento mais aprofundado sobre temáticas como o contexto histórico da pandemia gerada pelo Novo Coronavírus, também conhecido por Covid-19. Tal epidemia global apresenta grande potencial de proliferação em ambientes com aglomeração de pessoas, como as escolas e universidades. Além disso será possível compreender quais foram as implicações causadas na educação, uma vez que foram abordados temas quanto às alternativas encontradas para instituições educativas seguirem com as práticas de aulas, o que se refere ao ensino remoto emergencial, adotado em escolas mundo afora, bem como diversos cursos de extensão promovidos por institutos de ensino da rede pública e privada. Ademais de tais temáticas inovadoras para os modelos de ensino, estudou-se uma perspectiva relacionada aos problemas apresentados no ensino remoto, entre os quais pode-se destacar falta de infraestrutura adequada para vários estudantes de áreas rurais ou periféricas no Brasil, bem como a fadiga e a dificuldade em se manter conectado por longos períodos, por parte de alunos e docentes, no tocante às atividades remotas. Quanto à metodologia, este trabalho científico teve como base uma pesquisa de natureza qualitativa, com estudo da arte de temas voltados ao ensino, tecnologia e também sobre o período pandêmico. Enquanto resultados obtidos, pode-se perceber o estudo da problemática das transformações em sala de aula, como distanciamento social e diferenças entre a comunicação gerada por telas de computadores e celulares e o diálogo direto e pessoal. Desta forma, é necessário tratar de forma científica assuntos presentes, a fim de auxiliar no entendimento de como o processo educativo está sendo tratado, desde seus efeitos remotos até as diferentes particularidades do período de quarentena.
\end{abstract}

Palavras-Chave: Ensino Remoto, Aprendizagem à Distância, Educação Tecnológica.

\section{RESUMEN}

Este artículo académico fue idealizado desde reflexiones sobre la necesidad en generar discusiones y conocimiento más profundado sobre temáticas como el contexto histórico de la pandemia generada por el Nuevo Coronavirus, también conocido por Covid-19. Tal epidemia global presenta gran potencial de proliferación en ambientes con aglomeración de personas, como las escuelas y universidades. Además, será posible comprehender cuales fueron las implicaciones causadas para la educación, ya que fueron abordados temas sobre las alternativas encontradas para instituciones educativas siguieren con las prácticas de clases, lo que se refiere a la enseñanza remota de emergencia, adoptada en

\footnotetext{
${ }^{1}$ Tecnólogo em Gestão de Turismo, Instituto Federal de Pernambuco, guilhermesfpontes@gmail

${ }^{2}$ Técnico em Edificações, Instituto Federal de Pernambuco, dayanecamilelima@gmail.com

${ }_{3}^{3}$ Mestra em Gestão Ambiental, Instituto Federal de Pernambuco, simonedypaula@ gmail.col

4 Mestre em Gestão do Desenvolvimento Local Sustentável, Instituto Federal
}

derek.alves@ recife.ifpe.edu.br

${ }^{5}$ Mestre em Administração, Instituto Federal de Pernambuco, erick.viana@ recife.ifpe.edu.br

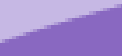


escuelas mundo afuera, bien como los diversos cursos de extensión promovidos por institutos de enseñanza de la rede pública y privada. Además de estas temáticas innovadoras para los modelos de enseñanza, fue estudiada una perspectiva relacionada a los problemas presentados en la enseñanza remota, entre los cuales se puede destacar la poca infraestructura adecuada para muchos estudiantes de áreas rurales o periféricas en Brasil, bien como la fatiga y la dificultad en mantenerse conectado por largos períodos, por parte de discentes y docentes, en relación a las actividades remotas. Cuanto a la metodología, este trabajo científico tiene como base una pesquisa de naturaleza cualitativa, con estudio del arte de temas vueltos a la enseñanza, tecnología y también sobre el periodo pandémico. Sobre los resultados obtenidos, se puede percibir el estudio de la problemática de los cambios en clase, como el distanciamiento social y diferencias entre la comunicación generada por pantallas de computadoras y móviles y el dialogo directo y persona. De este modo, es necesario comprender la forma científica de los asuntos presentes, a fin de auxiliar en entendimiento de cómo el proceso educativo está siendo tratado, desde los efectos remotos hasta las distintas particularidades del período de cuarentena.

Palabras Clave: Enseñanza Remota, Aprendizaje a Distancia, Enseñanza Tecnológica.

\begin{abstract}
This academic article was idealized after reflect about the needing to generate discussion and specified knowledge about themes like historical context of pandemic caused by New Coronavirus, also known as Covid-19. This global epidemic presented with great proliferation potential in places with people agglomerated, case of schools and Universities. Moreover, it will be possible to comprehend which were the problems caused in the education, once that themes related to the alternative found by the educative institutions to keep with classroom practice, referred to the emergently remote learning, adopted in schools around the world, as well diverse extension courses promoted by learning institutes, public or private. Moreover, these innovative themes for learning models, it was studied a perspective related to the problems presented in remote learning, whom questions can be explicated by the bad infrastructure for many students in rural and periphery areas in Brazil. As well tiring and difficulty to keep connected for long periods, independent if the person is student or professor, in case of remote activities. About the methodology, this scientific work had basis on a qualitative research, with art study in themes related to learning, technology and also pandemic period. About the results, it is possible to perceive the study of the changes in classroom, as social distancing and differences between communication generated by computer or cellphone screens and the direct and personal. This way, it is necessary to treat scientifically present topics, looking for how the educative process is being understood, since these remote effects until the different particularities from the quarantine period.
\end{abstract}

Keywords: Remote Learning, Distancing Learning, Technological Education.

\title{
INTRODUÇÃO
}

No final do ano de 2019, começou-se a divulgar informações por meio de portais de mídia sobre uma doença viral com alto potencial de contágio. A enfermidade, oriunda da província de Wuhan, na China, causada pelo Novo Coronavírus ou Covid-19, acarretou problemas mundiais, uma vez que o vírus se espalhou rapidamente em todo planeta. Em março de 2020, a Organização Mundial da Saúde denominou o surto como pandemia (UOL, 2020). Vale ressaltar, porém, que esta não foi a primeira ocasião de um vírus com proporções continentais, uma vez que ocorreram, previamente, a Peste Negra, do século XIV, e a Gripe Espanhola, iniciada após o final da Primeira Guerra Mundial, em 1918 (PASTERNAK, 2018; GALILEU, 2020).

Em decorrência da rápida transmissão do vírus, autoridades sanitárias de diversos 
países indicaram medidas como isolamento social, utilização de álcool gel (para higienização das mãos) e máscaras, com intuito de frear a proliferação, conter a pandemia e evitar a contaminação entre pessoas. Sendo assim, alguns estabelecimentos com grande potencial de ajuntamneto de indivíduos foram aconselhados a deixarem de atender presencialmente. As escolas e universidades, por serem ambientes nos quais geram grandes probabilidades de aglomerações, foram consideradas locais a se evitar presencialmente (SARAIVA, TRAVERSINI, LOCKMANN, 2020).

Sendo assim, as instituições de ensino, em diversos locais, optaram por realizar o ensino remoto, como forma de minimizar a perda das atividades acadêmicas e continuação das relações escolares. Embora não seja recente a prática de aulas não presenciais, não havia demanda significativa e nem todas as realidades tinham habilidades e conhecimento para utilizar tal sistema distanciado. Isto tudo ocasionou mudanças significativas nas relações sociais entre educadores e educandos, os quais se viram obrigados a não mais se encontrarem e precisaram utilizar novas metodologias educacionais, algo que aumentou a produtividade, gerando novas oportunidades (SARAIVA, TRAVERSINI, LOCKMANN, 2020).

Desta forma, este artigo acadêmico terá como objetivo compreender e analisar os desafios, bem como a crescente de novas possibilidades relacionadas ao ensino. Permitiu-se, pois, a comunidade acadêmica empoderar-se de plataformas virtuais, por conta das dificuldades em decorrência da pandemia. Os dados estudados a seguir foram extraídos, majoritariamente de revisão bibliográfica.

É importante salientar, que o intuito deste artigo é expor algumas das experiências e conclusões raciocinadas, mediante as pesquisas concretizadas, neste momento de distanciamento social. O estudo visa ajudar futuras análises desta fase de pandemia global e fortalecer novas descobertas sobre a área do ensino remoto que está sendo cada vez mais desbravada e que continuará na vida acadêmica das próximas gerações.

\section{FUNDAMENTAÇÃO TEÓRICA}

A fundamentação teórica do artigo será composta por duas etapas. Na primeira será realizada uma descrição histórica e problematização da questão de acesso à tecnologia por camadas socialmente excluídas na sociedade. Já a segunda etapa, descreve algumas das inovações a serem possibilitadas a partir do uso da tecnologia em períodos de ensino remoto e home office. 


\section{EDUCAÇÃO E TECNOLOGIA}

A tecnologia vem sendo uma ferramenta muito importante para a formação das sociedades contemporâneas. Dessa maneira, os avanços tecnológicos também geraram diversas contribuições para a educação moderna. Uma das primeiras demonstrações para desenvolver a educação à distância (EAD) foi iniciada a partir do século XIX, nos Estados Unidos, com matérias por correspondência em jornais. No Brasil, a difusão deste modelo aconteceu através de cursos por rádio (OLIVEIRA, 2019).

Como se percebe, já é possível verificar a disruptividade na educação como algo presente na sociedade, ao se utilizar a tecnologia como forma a aprimorar o aprendizado (ARAÚJO et al, 2017). Além disso, pode-se identificar a presença de uma nova forma de ensinar e aprender inovando e empreendendo em novos meios de interação entre discentes e docentes buscando atender às novas demandas da sociedade, como em atividades lúdicas nas próprias disciplinas tradicionais (COSTA, 2019).

Pensando nisso, é possível também recordar o conceito de educação empreendedora, isto é, "aquela que procura despertar nos alunos a vontade de inovar" (LIMA, 2017, p.15). O empreendedorismo, enquanto ação que visa suprir a dor de uma sociedade, na área da educação se possibilita à realização de novas soluções para desafios nas escolas (BAGGIO, BAGGIO, 2014).

Sendo assim, este artigo acadêmico visa trazer uma reflexão sobre a possibilidade de se reinventar em períodos distintos do habitual, isto é, uma análise sobre o que seria a aprendizagem em um novo normal, num período durante e após a pandemia. A partir disso, Amaral e Polydoro (2020) expõem que, no caso da universidade estudada pelas escritoras Universidade Estadual de Campinas, foi realizado um avanço nos sistemas digitalizados, com apoio à elaboração de vídeos, podcasts e conteúdos online, no sentido de auxiliar não somente os docentes, mas também os discentes a continuarem produzindo.

No entanto, Crawford et al (2020) entendem que não é simples o processo readaptação. Algumas das dificuldades relatadas por estes autores dizem respeito à total ou mesmo parcial falta de infraestrutura residencial adequada para o trabalho e estudo home office, ou seja, trabalho remoto. Já Huang et al (2020) recordam a dificuldade de certos grupos em utilizarem as redes de internet de maneira confiável. Além dessas problemáticas externas (2020, p.57) citam, algumas questões internas aos alunos, dentre o que podemos destacar: "os estudantes relataram dificuldade em gerenciar os estudos e necessidade de investir maior tempo para a realização das atividades e para apreensão do conteúdo". 
Ainda ressaltando os percalços trazidos pela dificuldade em se concentrar ou realizar atividades remotamente, junta-se ao fator que Oliveira (2020) aponta a distinção entre estudantes de escolas da rede pública se comparadas à rede privada. Esta autora cita que parcela significativa dos alunos oriundos de escolas estatais não possuem quaisquer dispositivos habilitados com acesso à internet para utilizarna educação.

O Centro Regional de Estudos para Desenvolvimento da Sociedade da Informação CETIC.BR (2020), entidade civil de direito privado, que faz parte do Núcleo de Informação e Coordenação do Ponto BR - NIC.BR, realizada anualmente pesquisa que possui o intuito de avaliar e compreender a quantidade e evolução de estudantes por todo o Brasil por meio do levantamento com mais de 11.361 estudantes das redes privada e pública, em todas as regiões geográficas brasileiras, urbana ou rural, além da participação de profissionais do ensino.

Sendo assim, esta pesquisa traz a problemática de que muitos dos estudantes do ensino público urbano não possuem tablet, computador de mesa ou portátil, uma vez que em torno de $40 \%$ não demonstra possuir nenhum desses aparelhos. Este dado traz a reflexão que, apesar de não ser maioria, parte significativa de estudantes foram prejudicados durante a pandemia, pois ficaram sem acesso a aulas remotas. Já na rede particular de ensino, ocorre uma situação distinta: aproximadamente $9 \%$ dos estudantes entrevistados não possuem acesso a computador ou tablet em suas residências. Quando o objeto de estudo passa a ser as escolas rurais, a dificuldade em acessar a rede é acentuada. Entre as instituições dessas regiões, $60 \%$ não possui acesso à internet, enquanto que $76 \%$ não apresentam meios para o acesso comunitário na grande rede. Já neste ponto, identifica-se que a falta de acesso à internet prejudica o desenvolvimento e isola ainda mais alunos da sala de aula.

Essa situação exposta sobre as diferenças relacionadas às escolas públicas e privadas nas áreas urbanas, bem como a disparidade percebida no tocante às escolas rurais, trazem reflexões sobre futuros sistemas educacionais. Além da necessidade de abordar a inclusão e democratização tecnológica é válido trazer a discussão de quais formas pode-se auxiliar no acesso dos estudantes a aparelhos que facilitem pesquisas, como é o caso dos tablets e computadores de mesa ou portáteis.

2. DESAFIOS E SOLUÇÕES DO ENSINO REMOTO PARA EDUCADORES E EDUCANDOS

Sene (2020), explica que neste contexto das dificuldades originadas pela pandemia, existe uma disparidade existente nas instituições de ensino em todo Brasil. A autora relata 
principalmente o quão difícultoso se tornou o período ao explicitar que no ensino público diversos alunos não possuem acesso adequado às atividades realizadas de forma remotamente.

Segundo, Sene (2020) na Universidade Federal de Pernambuco existe um total de $80 \%$ entre os profissionais técnicos ou docentes estão dispostos a realizar cursos visando o ensino remoto, isto é, aquele modelo de ensino no qual não há contato físico, discentes e docentes se encontram separados geograficamente a fim de terem a prática de classe (BEHAR, 2020).

$O$ intuito seria auxiliar na formação pessoal e desenvolvimento próprio e da comunidade acadêmica, bem como aumentar a capacitação pessoal visando uma maior qualidade acadêmica (PECHARKI, 2020). Uma outra solução apresentada para contornar a crise educacional gerada é a abertura de licitações e editais para os estudantes carentes possuírem acesso à compra ou empréstimo de materiais tecnológicos a fim de acompanharem as aulas.

Além disso, outras iniciativas inovadoras surgiram, como é o caso de maratonas no estilo hackathon, (GUIZARDI et al, 2018), a exemplo do Hacking Help Covid, primeira edição da maratona na condição virtual (ANPROTEC, 2020), ocorridas no mês de maio de 2020 contribuíram na busca por soluções inovadoras, a partir de situações reais propostas, visando melhor lidar com a problemática durante e após a pandemia.

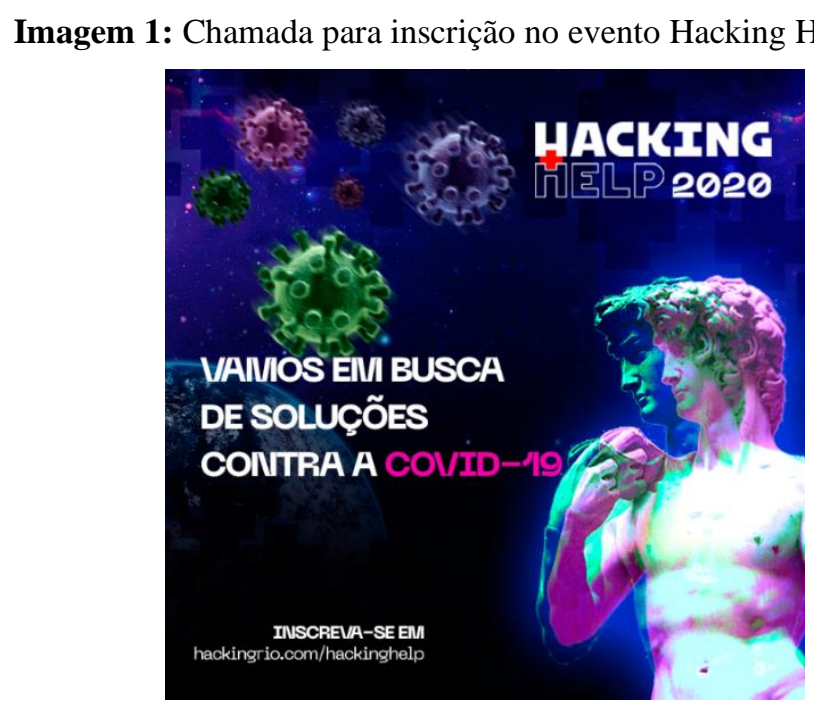

Fonte: Twitter UERJ (2020)

A tecnologia, cada vez mais, torna-se uma ferramenta importante em nossa sociedade globalizada (INOVAPARQ, 2016) possibilitando conferir avanços em todas as áreas do conhecimento. Porém, mesmo com a presença marcante de tecnologias em diversas camadas da sociedade, nem todos possuem acesso a ela.

Vale ressaltar, que um estudo proposto pelo Comitê Gestor da Internet, com dados 
levantados pela TIC Domicílios, o qual também faz parte do grupo CETIC.BR apontam que $30 \%$ dos brasileiros não possuíam acesso à internet em 2019. Esta situação, segundo Mattas e Chagas (2008), é histórica no Brasil, não apenas sobre a temática da tecnologia, mas também relacionado à distribuição desigual de renda e riquezas no país.

Tais dados comprovam, inclusive, que a renda dos cidadãos está ligada ao seu acesso à tecnologia. Para justificar tal informação, é possível analisar, entre outras adversidades, que a infraestrutura que permite o acesso às linhas telefonicas e o aumento do número de computadores por habitantes (assim como a quantidade deles conectados à internet) mostra-se ainda bastante insuficiente (MATTAS; CHAGAS, 2008, p. 80).

Assim, com a situação mundial apresentada pela pandemia, foi demonstrada a importância do estudo de políticas educacionais em relação a acessibilidade e democratização da tecnologia entre estudantes (SAE DIGITAL, 2020).

Desse modo, diversos estudos começaram a ser promovidos, buscando soluções para situações advindas dessa nova problemática e também apontando os benefícios das mesmas a serem utilizadas como ferramenta de ensino na nossa sociedade.

Tais pesquisas foram de grande importância para o momento pandêmico, mas também irão ajudar as futuras possibilidades de ensino e a sociedade no geral. Com a pandemia, o uso de tecnologias na vida do cidadão brasileiro, de acordo com o registro da empresa Akamai, teve um aumento de 112\%, no Brasil (BIELASKI, 2020). Essa necessidade de avanço nos meios educacionais e tecnológicos foram analisadas e geraram diversos questionamentos e respostas.

Assim, as adaptações de diversas atividades cotidianas foram sendo feitas por todos. Essas soluções encontradas no uso das redes sociais, videoconferências e modalidade de Educação a Distância (EAD), ficaram cada vez mais comuns. Isso demonstrou a solicitação, por parte do povo brasileiro, em relação a mudanças e avanços da tecnologia na educação. Sendo essas modificações não só urgentes para o presente momento, mas também, como possíveis modelos permanentes no futuro como a democratização ao acesso a internet.

Vale lembrar, que o uso das Tecnologias Digitais da Informação e Comunicação (TDIC) nos ambientes educacionais facilita o processo de ensino e aprendizagem e amplia a possibilidade da inclusão social. Mas, para haver um resultado favorável no processo de ensino, este deverá ser realizado através de estratégias arrojadas e eficientes que venham ao encontro com as premências das disciplinas e discentes, respeitando as exigências estabelecidas pelas instituições de ensino (OLIVEIRA; SILVA, 2015).

Os resultados favoráveis, citados anteriormente, estão interligados com as formas de $[122]$ 
relação entre professor, aluno e família. A presença da família no auxílio aos estudos dos alunos tende a resultar um significativo benefício para o desenvolvimento dos discentes, nesse novo modelo educacional. Além disso, outros métodos de revisão e monitoramento de aprendizagem do estudante tiveram de ser desenvolvidos e adotados, de forma conjunta, tentando adequar a relação entre responsáveis, crianças e escola (HEDLUND; AMARAL, 2020).

Com o avanço das tecnologias de ensino, nesse período, educadores tiveram maior conexão entre discentes. A utilização de jogos, aplicativos e outra plataformas mais interativas se tornou comum, trazendo experiências mais modernas para a sala de aula virtual. Ademais, professores e alunos puderam ter maior contato com as famílias.

Apesar disso, foram apontados problemas como a não inovação na forma de educar, com professores utilizando os mesmos métodos tradicionais, nas circunstâncias atuais (CORDEIRO, 2020): “A maioria dos professores imigrantes digitais que se inseriram no mundo da tecnologia, têm uma forma de ensinar que nem sempre está em sintonia com o modo como os nativos aprendem melhor, ou, pelo menos, que lhes desperta maior interesse". (BACICH, 2015, p.31)

Visto isso, depreende-se que as dificuldades estariam presentes, por ser uma situação atípica para todos. Contudo o crescimento e avanço tecnológico na educação deve ser reconhecido e estudado ainda mais. Assim, a comunicação, forma de avaliação e diversos outros tópicos devem ser debatidos para a melhoria desse ensino por meio da tecnologia e no avanço da educação tradicional (BARBOSA et al; HEDLUND; CORDEIRO, 2020).

\section{METODOLOGIA}

Este artigo teve, de forma predominante, os procedimentos metodológicos com exercício de revisão de literatura e estado da arte. Desta forma, a principal característica do trabalho é ser uma pesquisa de natureza qualitativa, isto é, o pesquisador procura ir a campo para estudar determinado assunto, sem pré julgamentos e analisando mais de um posicionamento (GODOY, 1994).

De acordo com Lara e Molina (2011), este tipo de pesquisa já é praticada há algumas décadas no Brasil, sendo que é necessário interpretar os dados e conceitos para se esclarecer de forma fundamentada o que está sendo exposto no texto corrido (OLIVEIRA, 2009). Ainda nessa linha de pensamento, Richardson (1999) compreende a coleta de informações no processo exploratório como parte da ciência. 
Após este entendimento da tipologia da pesquisa realizada, é importante também descrever o processo pelo qual foi desempenhada a busca de informações. Ao considerar que a Pandemia do Novo Coronavírus atingiu maiores proporções no ano de 2020, é dificultoso encontrar amplo referencial teórico que embase detalhadamente os efeitos, motivos e possíveis consequências sobre o que o distanciamento social causa, bem como o efeito de se trabalhar por tempo longo em estilo home office. O caso do ensino remoto, que utiliza diversas plataformas e desgasta os envolvidos, é uma das situações que ainda não há muito estudo a respeito.

Além disso, ao se realizar apanhados históricos e conceitos que comprovam a disruptividade do ensino remoto, embora emergencial, também pode-se denominar a característica de interpretação de dados da realidade, conferindo à pesquisa científica o seu caráter qualitativo.

\section{RESULTADOS E DISCUSSÕES}

É geralmente posto de forma consensual que a educação exerce forte influência nas transformações da sociedade, sendo a responsável pelo desenvolvimento da capacidade cognitiva e crítica do indivíduo. Além disso, a educação atesta o grau de desenvolvimento da sociedade, através de certos índices (PINTO, 2019). Diante disso é importante destacar que o rompimento de processos ou mudanças bruscas nos mesmos, acabam por trazer consequências nada satisfatórias ao crescimento social do país. (DIAS; PINTO 2019)

De acordo com Freire (1979), quando o homem compreende a sua realidade, pode levantar hipóteses sobre o desafio desse meio e procurar soluções. Assim, pode transformá-la e o seu trabalho pode criar um mundo próprio: seu eu e as suas circunstâncias. Desse modo, a partir da busca por soluções e percebendo-se que o período pandêmico acarretou transformações no fazer e ensinar da educação brasileira, diversos estudos estão sendo feitos.

Objetiva-se, pois, encontrar possíveis respostas para os problemas decorrentes dificuldades impostas pela contraindicação ao ensino presencial, necessitantdo-se adequação a metodologias mais adequadas para prosseguir com a prática do ensino para crianças, jovens e adultos. Para tanto, a utilização em ampla escala do ensino remoto tornou-se um novo horizonte na sociedade brasileira. É necessário, por isso, compreender como vem ocorrendo a adaptação de docentes e discentes no ensino remoto, bem como verificar quais estratégias adotadas por meio das plataformas utilizadas nas aulas.

Dessa forma, percebe-se que as mudanças de metodologias educacionais são visíveis, 
trazendo reflexões sobre o futuro do ensino tradicional e remoto e qual novo modelo se adequar. Pode-se pensar, desta forma, no ensino híbrido ou metodologias intituladas como sala de aula invertida (SANTOS, SANTOS; 2020). Lembra-se, pois, que tais inovações geram aprendizados valiosos à sociedade, por aliar novas possibilidades tecnológicas às salas de aula. observamos que as adversidades estarão presentes, quando considera-se mudar as metodologias educacionais de forma mais imediata e, possivelmente, permanente quando inicia-se debates sobre o futuro do ensino tradicional e remoto. Apesar disso, é importante lembrar das inovações e aprendizados trazidos para nós como sociedade, por meio desse atípico período que estamos vivenciando.

Com todas mudanças, essas discussões realizadas sobre a metodologia de ensino remoto, que apesar de não ser nova, nunca teve tanta influência e importância em nossa sociedade até os dias de hoje. Assim, análises comportamentais e técnicas puderam ser estudadas para a melhoria no entendimento e na prática da nova atividade. Como vimos, percebeu-se as habituais situações de cansaço e estresse diante das aulas síncronas ou assíncronas, videoconferências e outros (POLLO, 2020). Esse processo tem sido intitulado de Zoom Fatigue, traduzido literalmente por fadiga de Zoom, uma plataforma comumente utilizada para videoconferências (FOLHAPRESS, 2020).

Tais sensações foram explicadas por diversos estudiosos, a psicóloga Maluh Duprat, pesquisadora do Janus (Laboratório de Estudos de Psicologia e Tecnologias da Informação e Comunicação) da PUC-SP, cita a causa de algumas, como a dificuldade da leitura da linguagem corporal é uma delas.

As dificuldades vão além da comunicação, mas também estão relacionadas com a falta de preparo para o uso de tecnologias por parte dos professores. Como mostra uma pesquisa do Instituto Península, realizada com 7734 professores em todo o Brasil, apontou que $88 \%$ dos professores nunca tinha dado aula à distância de forma remota e 83,4\% não se sentiam preparados. Essa situação resulta em casos de falhas na apresentação das aulas, problemas com áudio e som dos aparelhos, dificuldades na correção de atividades, entre outros (OLIVEIRA, 2020).

Algumas situações ligadas ao emocional de cada docente e discente, também afetaram a eficiência das atividades. O suporte emocional não foi uma medida presente na vida de todos educadores e estudantes. Levando em consideração a atual pandemia, problemas relacionados com a ansiedade e outros problemas psicológicos ou até mesmo a perda de entes queridos, foram constantes, fazendo com que esse apoio mental adquirisse grande importância na vida de todos (SALAS, 2020). 
Ainda que existam os problemas decorrentes da pandemia, é necessário pensar novas possibilidades de voltar à interação física, uma vez que os seres humanos, como diria Aristóteles, é um animal social (REDAÇÃO PSICANÁLISE CLÍNICA, 2020). Assim sendo, uma das possibilidades de se retornar ao convívio em sala de aula é por meio de cadeiras com distanciamento social. Tal medida visa a diminuição de contato e auxilia a não proliferação do Novo Coronavírus.

Ademais da necessidade de reinserção no ambiente escolar, é possível pensar em uma intensificação do já proposto ensino híbrido, isto é, uma fusão entre as práticas presenciais com aquelas remotas, ao se utilizar os métodos tecnológicos para a educação. Isto ajuda a evoluir e cada vez mais tornar o ensino inovador e digital, por meio da tecnopedagogia, ou seja, a aplicação conjunta de ferramentas tecnológicas à educação. Resultando, assim, em aulas que auxiliem e tornem indispensável a evolução do ensino cotidiano (ZEDNIK et al, 2014).

Imagem 2: Sala de aula com distanciamento social

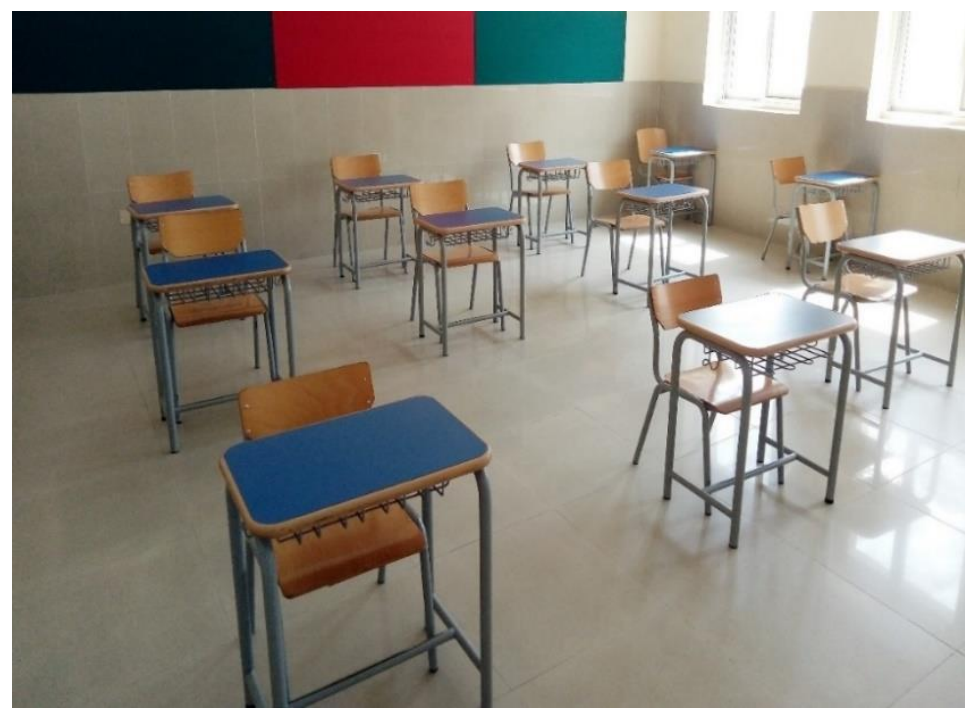

Fonte: Google Imagens - Pixa Bay

Ademais, ao analisar as muitas conexões feitas entre alunos e professores por meio de uma educação mais dinâmica e interativa, com o uso de plataformas virtuais diversas. Além também, o engajamento das famílias na educação daqueles do qual eram responsáveis teve, de acordo com o Conselho Nacional de Educação (CNE, 2020), um papel ainda mais importante na elaboração de um vínculo forte entre escola e aluno, para que esse não obtivesse retrocessos no seu desenvolvimento educacional (AMARAL, 2020).

Portanto, as situações inusitadas foram presentes durante esse período atípico da sociedade moderna. Apesar das dificuldades, essas trouxeram também desenvolvimento e 
inovação. Aprender a ensinar exige que os professores reflitam e compreendam a aprendizagem de maneiras bem diferentes daquilo que aprenderam com a própria experiência como estudantes (HAMMERNESS et al., 2019).

\section{CONCLUSÃO}

Entende-se, portanto, a importância e influência que a tecnologia vem apresentando na sociedade moderna. Desse modo, torna-se importante perceber que durante esse período de pandemia mundial, sua evolução foi significativa, entretanto essa conclusão ainda não possui dados concretos, já que no momento atual deste artigo, está ainda não foi cessada. Apesar disso, diante das informações discutidas e explicitadas, vemos que esta adquiriu um impacto de valor para os modelos de educação atuais e futuros.

Ao entender as aulas remotas enquanto saída plausível para estudantes e professores estarem em contato no compartilhamento do saber, também foi analisada uma série de deficiências e novas possibilidades que o período trouxe. Um exemplo de deficiência seria a fadiga por elevados tempos em conexão online, enquanto uma questão mais positiva volta-se para o uso da tecnologia como forma de avançar a educação, por meio da disruptividade empreendedora de cursos e maratonas de extensão.

Por fim, a discussão trazida tem potencial para exploração cada vez maior, desde soluções e até análises de lições tiradas pelo isolamento social forçado. Traz-se à tona questões voltadas à desigualdade de renda presente no Brasil e em diversos países, que o distanciamento acentuou economicamente e dificultou o aprendizado de populações menos favorecidas por condições mínimas de avanço no aprendizado. Mesmo assim, é válido lembrar que essas adversidades não devem ser desprezadas, mas, sim, levadas a busca de soluções para o avanço educacional, tecnológico e social.

\section{REFERÊNCIAS}

AMARAL, E.; POLYDORO, S. Os desafios da mudança para o ensino remoto emergencial na graduação na UNICAMP- Brasil. Linha Mestra. n. 41 a, p.52-62, 2020.

AMARAL, H. U. do. Relação Das Escolas Com as Famílias Durante a Pandemia. Disponível em:camadaseducacionais.com.br/blog/relacao-das-escolas-com-as-familiasdurante-a-pandemia. Acesso em: 2 Nov. 2020.

ARAÚJO, S. P. de. Tecnologia na educação: contexto histórico, papel e diversidade. IV 
Jornada de Didática III Seminário de Pesquisa do CEMAD, 2017.

ANPROTEC. Anprotec apoia o Hacking Help 2020 em busca de soluções que minimizem os efeitos da Covid-19. Disponível em: https://anprotec.org.br/site/2020/05/anprotec-apoia-ohacking-help-2020-em-busca-de-solucoes-que-minimizem-os-efeitos-da-covid-19/ Acesso em: 01 de novembro de 2020.

BAGGiO, A. F.; BAGGIO, D. K. Empreendedorismo: Conceitos e Definições. Rev. de Empreendedorismo, Inovação e Tecnologia, v. 1, n. 1, p. 25- 38, 2014.

BARBOSA, J. F. M. et al. Experiências no processo de ensino - aprendizagem -avaliação durante a pandemia. In: Anais do 39 Seminário de Atualizações de Práticas Docentes. 2020.

CETIC BR. Escolas estão mais presents nas redes sociais, mas plataformas de aprendizagem a distância são pouco adotadas. Disponível em: https://cetic.br/pt/noticia/escolas-estao-mais-presentes-nas-redes-sociais-mas-plataformas-deaprendizagem-a-distancia-sao-pouco-adotadas/ Acesso em: 05 de novembro de 2020.

COSTA, T. T. Empreendedorismo No Ensino Básico e Superior Já é Uma Realidade. Disponível em: www.correiobraziliense.com.br/app/noticia/comunidadeei/2019/07/23/noticias-comunidadeei,773153/empreendedorismo-no-ensino-basico-esuperior-ja-e-uma-realidade.shtml. Acesso em: 31 Out. 2020.

CRAWFORD, J. et al. Covid-19: 20 countries' higher education intra-period digital pedagogy responses. Journal of Applied Learning and Teaching, v. 3, n. 1, 2020.

DESENVOLVIDO POR IPOOMWEB - IPOOMWEB.COM.BR. Uso Da Internet Cresce 112\% No Brasil Durante Pandemia | ClicCamaquã. Disponível em:www.cliccamaqua.com.br/noticia/54862/uso-da-internet-cresce-112-no-brasil-durantepandemia.html. Acesso em: 31 Out. 2020.

DIÁRIO DO COMÉRCIO. 8,8 Milhões de Brasileiros Estão Em Home Office - Diário Do Comércio." Disponível em: diariodocomercio.com.br/economia/88-milhoes-de-brasileirosestao-em-home-office/. Acesso em: 1 Nov. 2020.

DUTRA, F. Artigo: O Ensino Remoto Emergencial e a Educação a Distância Coronavírus. Disponível em: www.ufrgs.br/coronavirus/base/artigo-o-ensino-remotoemergencial-e-a-educacao-a-distancia/. Acesso em: 2 Nov. 2020.

FREIRE, P. Educação e mudança. 12 ed. Paz e Terra, 1979.

FUNDAÇÃO TELEFÔNICA VIVO. Pesquisa TIC Educação 2019 Mostra o Impacto Da Tecnologia No Aprendizado. Disponível em: fundacaotelefonicavivo.org.br/educacao-doseculo-xxi/pesquisa-tic-educacao-2019-mostra-o-impacto-da-tecnologia-no-aprendizado/.

Acesso em: 31 Out. 2020.

G1 RIO. Hacking.Rio promove hackaton online para desenvolver soluções de combate à Covid-19. Disponível em: https://g1.globo.com/rj/rio-dejaneiro/noticia/2020/05/18/hackingrio-promove-hackathon-online-para-desenvolver-solucoesde-combate-a-covid-19.ghtml Acesso em: 31 de outubro de 2020. 
GALILEU. Peste Bubônica: 5 Pontos Para Entender o Que é a Doença. Disponível em: revistagalileu.globo.com/Ciencia/Saude/noticia/2020/07/peste-bubonica-5-pontos-paraentender-o-que-e-doenca.html. Acesso em: 1 Nov. 2020.

GODOY, A. S.. Pesquisa Qualitativa: tipos fundamentais. RAE. Revista de Administração de Empresas JCR, São Paulo, v. 35, n.3, p. 20-29, 1995.

GUIZARDI, F.L; SANTOS, K.G; LEMOS, A.S.P; SEVERO, F.M.D . Maratonas hackers no Brasil com desafios no campo da Saúde. São Paulo: Interface (Botucatu), 2018.

Cordeiro, K. M. D. A. (2020). O Impacto da Pandemia na Educação: A Utilização da Tecnologia como Ferramenta de Ensino.Disponível em: http://idaam.siteworks.com.br/jspui/bitstream/prefix/1157/1/O\%20IMPACTO\%20DA\%20PA NDEMIA\%20NA\%20EDUCA\%c3\%87\%c3\%830\%20A\%20UTILIZA\%c3\%87\%c3\%830\% 20DA\%20TECNOLOGIA\%20COMO\%20FERRAMENTA\%20DE\%20ENSINO.pdf Acesso em: 04 de novembro de 2020

HEDlund, A. O Papel Da Família e Sua Relação Com a Escola No Ensino Remoto | Edify Education - Programa Bilíngue. Disponível em: www.edifyeducation.com.br/blog/opapel-da-familia-e-sua-relacao-com-a-escola-no-ensino-remoto/. Acessoem: 1 Nov. 2020.

HUANG, R. H. et al. Handbook on facilitating flexible learning during educational disruption: The Chinese experience in maintaining undisrupted learning in COVID-19. Outbreak Beijing: Smart Learning Institute of Beijing Normal University, 2020.

INOVAPARQ. O Impacto Das Novas Tecnologias Na Sociedade. Disponível em: inovaparq.com.br/o-impacto-das-novas-

tecnologias/\#: :text=A\%20tecnologia\%20vem\%20influenciando\%20a,uma\%20maior\%20bus ca\%20por\%20informa\%C3\%A7\%C3\%B5es. Accessed 31 Out. 2020.

LARA, A. M. B. ; MOLINA, Adão Aparecido . Pesquisa Qualitativa: apontamentos, conceitos e tipologias. In: Cèzar de Alencar Arnaut de Toledo; Maria Teresa Claro Gonzaga. (Org.). Metodologia e Técnicas de Pesquisa nas Áreas de Ciências Humanas. Maringá: EEduem, 2011, v. 01, p. 121-172.

LIMA, J. de A. Educação Empreendedora e Educação Escolar: Uma Aplicação no Ensino Médio. 2017. 40 p. Trabalho de Conclusão de Curso, (Especialização), Especialização em Educação Empreendedora, Pontifícia Universidade Católica do Rio de Janeiro, Rio de Janeiro, 2017.

MATTOS, F. A. M. de.; CHAGAS, G. J. do N. Desafios para a inclusão digital no Brasil. Perspectivas em Ciência da Informação. v. 13, n. 1, p. 67-94, jan/abr. 2008.

MOVIMENTO DE INOVAÇÃO NA EDUCAÇÃO. O Que o Uso Das Tecnologias Digitais No Ensino Remoto Evidência Sobre o Futuro Da Escola - Movimento de Inovação Na Educação. Disponível em: movinovacaonaeducacao.org.br/noticias/o-que-o-uso-dastecnologias-digitais-no-ensino-remoto-evidencia-sobre-o-futuro-da-escola/. Nov. 2020. 
OLIVEIRA, A. Uninter oferece 12 cursos de extensão gratuitos durante pandemia de coronavírus. Disponível em: https://www.uninter.com/noticias/uninter-oferece-12-cursos-deextensao-gratuitos-durante-a-pandemia-de-coronavirus Acesso em: 02 de novembro de 2020.

OLIVEIRA, B. Como Surgiram Os Cursos de Ensino a Distância? | Blog CathoEdu. Disponível em: www.catho.com.br/educacao/blog/como-surgiram-os-cursos-de-ensino-adistancia-no-brasil-e-no-

mundo/\#: :text=J\%C3\%A1\%20outros\%20acreditam\%20que $\% 20 \mathrm{o}$,conhecimento $\% 20$ por $\% 20$ meio\%20do\%20r\%C3\%A1dio. Acesso em: 1 Nov. 2020.

OLIVEIRA, C. L. Um apanhado teórico-conceitual sobre a pesquisa qualitativa: tipos, técnicas e características. In: Travessias, 2008, Cascavel-PR. Anais: UNIOESTE, 2009.

OLIVEIRA, E. Quase 40\% Dos Alunos de Escolas Públicas Não Têm Computador Ou Tablet Em Casa, Aponta Estudo. Disponível em: g1.globo.com/educacao/noticia/2020/06/09/quase-40percent-dos-alunos-de-escolas-publicasnao-tem-computador-ou-tablet-em-casa-aponta-estudo.ghtml. Acesso em: 31 Out. 2020.

OLIVEIRA, M. V. Professores Pedem Apoio Técnico e Psicológico Durante a Quarentena - PORVIR. Disponível em: porvir.org/professores-pedem-apoio-tecnico-epsicologico-durante-a-quarentena/. Acesso em: 1 Nov. 2020.

PASTERnAK, N. Gripe Espanhola: 100 Anos Da Mãe Das Pandemias. Disponível em: saude.abril.com.br/blog/cientistas-explicam/gripe-espanhola-100-anos-da-mae-daspandemias/. Acesso em: 2 Nov. 2020.

PECHARKI, J. Cursos Online: 9 Sites Para Melhorar o Currículo Durante a Pandemia. Disponível em: www.gazetadopovo.com.br/gazz-conecta/plataformas-de-cursos-online-paramelhorar-o-curriculo/. Acesso em: 2 Nov. 2020.

PINTO, D. de O. Pisa - Ranking de Educação Mundial: Entenda Os Dados Do Brasil. Disponível em: blog.lyceum.com.br/ranking-de-educacao-mundial-posicao-do-brasil/. Acesso em: 2 Nov. 2020.

POLLO, L. Efeito no cérebro: por que todo mundo está exausto de conversar po vídeo. Disponível em: https://tab.uol.com.br/noticias/redacao/2020/05/08/por-que-todo-mundo-estaexausto-de-conversar-por-video.htm?cmpid=copiaecolaAcesso em: 03 de novembro de 2020.

PORTAL IFPE. Campus oferece extensão online em diversas áreas durante quarentena. Disponível em: https://portal.ifpe.edu.br/campus/recife/noticias/campus-ofereceextensao-online-em-diversas-areas-durante-a-quarentena Acesso em: 01 de novembro de 2020.

RABELlO, M. E. Lições Do Coronavírus: Ensino Remoto Emergencial Não é EAD. Disponível em: desafiosdaeducacao.grupoa.com.br/coronavirus-ensino-remoto/. Acesso em: 1 Nov. 2020.

REDAÇÃO PSICANÁLISE CLÍNICA. O Homem é Um Ser Social: 3 Teorias Científicas. Disponível em: www.psicanaliseclinica.com/o-homem-e-um-ser-social/. Acesso em: 30 Out. 2020. 
REDAÇÃO RBA. Brasil Da Pandemia: Quase 9 Milhões Em 'home Office' e 15 Milhões Afastados - Rede Brasil Atual. Disponível em: www.redebrasilatual.com.br/economia/2020/06/brasil-pandemia-home-office/. Acesso em: 31 Out. 2020.

RICHARDSON, R. J. Pesquisa social: métodos e técnicas. 3. ed. São Paulo: Atlas, 1999.

SAE DIGITAL. Educação e Coronavírus - Quais São Os Impactos Da Pandemia? - SAE Digital. Disponível em: sae.digital/educacao-e-coronavirus/. Acesso em: 2 Nov. 2020.

SALAS, P. Ansiedade, Medo e Exaustão: Como a Quarentena Está Abalando a Saúde Mental Dos Educadores. Disponível em: novaescola.org.br/conteudo/19401/ansiedademedo-e-exaustao-como-a-quarentena-esta-abalando-a-saude-mental-dos-educadores. Acesso em: 31 Out. 2020.

SANTIAGO, E. G. Vertentes teóricas sobre empreendedorismo em Schumpeter, Weber e Mcclelland: novas referências para a sociologia do trabalho. Revista de Ciências Sociais, v. 40. n. 2, p. 87 - 103, 2009.

SANTOS, V. B. O. dos; SANTOS, S. M. P. Ensino remoto pelo edmodo em tempos de pandemia. Revista Carioca de Ciência, Tecnologia e Educação. Rio de Janeiro: v. 5, n. especial, 2020.

SARAIVA, K.; TRAVERSINI, C. LOCKMAN, K. A educação em tempos de Covid-19: ensino remoto e exaustão docente. Práxis Educativa. v. 15, 2020.

SENE, A. Ensino remoto: desafios para o ensino público brasileiro durante a pandemia da Covid-19. Disponível em: http://www.adufepe.org.br/ensino-remoto-desafios-para-oensino-publico-brasileiro-durante-a-pandemia-da-covid-19/ Acesso em: 05 de novembro de 2020.

Tic Educação $2019 . \quad$ Disponível em: https://cetic.br/media/analises/tic_educacao_2019_coletiva_imprensa.pdf Acesso em: 04 de novembro de 2020

UOL. Coronavírus: Cuidados Que Você Deve Ter Para Se Prevenir Da Covid-19. Disponível em: www.uol.com.br/vivabem/faq/coronavirus-cuidados-que-voce-deve-ter-parase-prevenir-da-covid-19.htm. Acesso em: 2 Nov. 2020.

---. Coronavírus Na China: Perguntas e Respostas Sobre a Doença. Disponível em: www.uol.com.br/vivabem/noticias/bbc/2020/01/22/coronavirus-na-china-perguntas-erespostas-sobre-a-doenca-que-matou-6.htm. Acesso em: 1 Nov. 2020.

---. Efeitos No Cérebro: Por Que Todo Mundo Está Exausto de Conversar Por Vídeo. Disponível em: tab.uol.com.br/noticias/redacao/2020/05/08/por-que-todo-mundo-estaexausto-de-conversar-por-video.htm. Acesso em: 2 Nov. 2020.

---. Efeitos No Cérebro: Por Que Todo Mundo Está Exausto de Conversar Por Vídeo. Disponível em: tab.uol.com.br/noticias/redacao/2020/05/08/por-que-todo-mundo-esta- 
exausto-de-conversar-por-video.htm. Acesso em: 31 Out. 2020.

---. Proliferação de Vírus Acelera e Gera $20 \%$ de Casos Severos e Críticos. Disponível em: noticias.uol.com.br/colunas/jamil-chade/2020/03/20/coronavirus-pode-gerar-20-de-casosseveros-ou-criticos-diz-oms.htm. Acesso em: 1 Nov. 2020.

ZEDNIK, H. et al. Tecnologias Digitais na Educação: proposta taxonômica para apoio à integração da tecnologia em sala de aula. In: Anais do Workshop de Informática na Escola. 2014, p. 507-516. 